\title{
A Revolutionary Idea
}

\section{Planning an Epic Hamil--Con}

Katie Guzek

If you've lived under a rock for the past year or two, you probably haven't heard the catchy, rappy funes from LinManuel Miranda's Broadway blockbuster Hamilton. But you didn't have to live in New York to catch Revolutionary fever-it seems those infectious tunes about Alexander Hamilton and his contemporaries were everywhere-and no age was immune. Even though the lyrics had some sass, even elementary school kids were learning their history
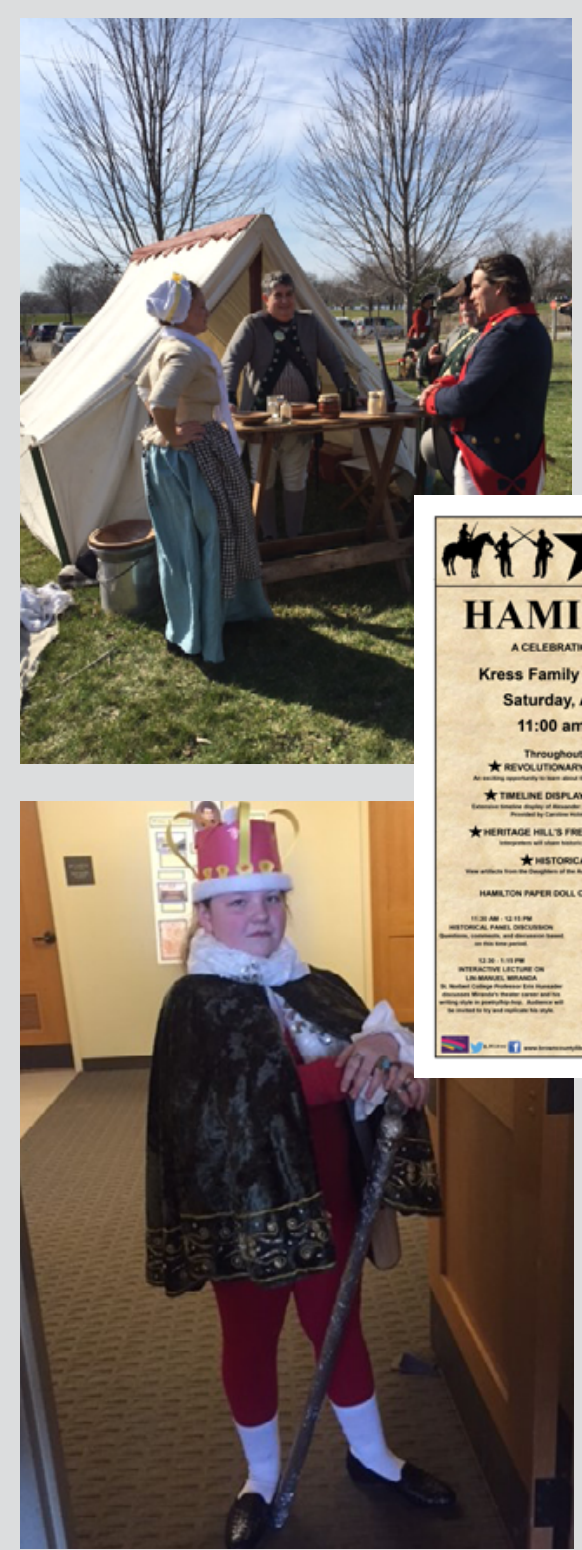
in a novel way and singing along.

Why not capitalize on that success at a library? That was exactly what several of us librarians at Brown County Library-all the way in Northeastern Wisconsin, far from the throngs of Broadway-thought. So in late 2016 we began planning what we hoped would be our epic Hamil-Con.

The objective of Hamil-Con was to increase people's appreciation and enjoyment of the musical. We wanted to achieve this by giving participants large-scale interactive structured and unstructured opportunities to learn more about the history and theatricality surrounding the play.

Our program, held on a Saturday in April 2017, drew more than four hundred attendees of all ages. The day featured many components-like the timeline of Hamilton's life and artifacts from the DAR (Daughters of the American Revolution) Museum in Washington, DC, and our local Neville Public Museum. It also included an authentic Revolutionary War encampment behind our library; a French fur-trading post presented by Heritage Hill, a living history museum in Green Bay; and a lecture by a St. Norbert College professor about creator Lin-Manuel Miranda.

But one of the most popular events was a live sing-a-long of songs from Hamilton-in which all ages, from age four to seniors, participated and, not surprisingly, knew all the words by heart!

This program engaged children, teens, adults, and seniors. Combining history and music and presenting it in an interactive way kept the audience engaged and eagerly participating.

Top left: Revolutionary War re-enactors set up camp outside the Kress Family Branch Library in De Pere, Wisconsin. Bottom left: Young Sophia was a stunning King George! Bottom right: One of the re-enactors, complete with gun and tri-corner hat. Center: The library's promotional poster echoed the Broadway play's look.

Katie Guzek is a Youth Services Librarian at Brown County Library in Green Bay, Wisconsin. 